\title{
Targeting of functional antibody-CD59 fusion proteins to a cell surface
}

\author{
Hui-fen Zhang, ${ }^{1}$ Jinghua Yu, ${ }^{1}$ Ednan Bajwa, ${ }^{1}$ Sherie L. Morrison, ${ }^{2}$ \\ and Stephen Tomlinson ${ }^{1}$ \\ ${ }^{1}$ Department of Pathology, New York University Medical Center, New York, New York 10016, USA
${ }^{2}$ Department of Microbiology and Molecular Genetics, University of California at Los Angeles,
Los Angeles, California 90095, USA
}

Address correspondence to: Stephen Tomlinson, Department of Pathology, MSB 126, New York University Medical Center, 550 First Avenue, New York, New York 10016, USA. Phone: (212) 263-8514; Fax: (212) 263-8179; E-mail: tomlis01@ popmail.med.nyu.edu

Received for publication July 16, 1998, and accepted in revised form November 3, 1998.

Complement is involved in the pathogenesis of many diseases, and there is great interest in developing inhibitors of complement for therapeutic application. CD59 is a natural membrane-bound inhibitor of the cytolytic complement membrane attack complex (MAC). In this study, the preparation and characterization of antibody-CD59 (IgG-CD59) chimeric fusion proteins are described. Constructs were composed of soluble CD59 fused to an antibody-combining site at the end of $\mathrm{C}_{\mathrm{H}} 1$, after the hinge $(\mathrm{H})$, and after $\mathrm{C}_{\mathrm{H}} 3 \mathrm{Ig}$ regions. The antigen specificity of each construct was for the hapten 5-dimethylaminonaphthalene-1-sulfonyl (dansyl). Correct folding of each IgG-CD59 fusion partner was indicated by recognition with anti-CD59 antibodies specific for conformational determinants and by IgG-CD59 binding to dansyl. The IgG-CD59 fusion proteins all bound specifically to dansyl-labeled Chinese hamster ovary cells and provided targeted cells, but not untargeted cells, with effective protection from complement-mediated lysis. Data indicate that CD59 must be positioned in close proximity to the site of MAC formation for effective function, and that modes of membrane attachment other than glycophosphatidylinositol linkage can affect CD59 functional activity.

J. Clin. Invest. 103:55-61 (1999).

\section{Introduction}

Activation of complement via either the classical or alternative pathway results in the generation of $\mathrm{C} 3$ convertase, a central enzymatic complex of the complement cascade that cleaves serum C3 into C3a and C3b. The $\mathrm{C} 3 \mathrm{~b}$ product can bind covalently to an activating surface and can participate in the further generation of $\mathrm{C} 3$ convertase (amplification loop). C3 convertases also participate in the formation of $\mathrm{C} 5$ convertase, a complex that cleaves serum C5 to yield C5a and C5b. Formation of $\mathrm{C} 5 \mathrm{~b}$ initiates the terminal complement pathway, resulting in the sequential assembly of complement proteins $\mathrm{C} 6, \mathrm{C} 7, \mathrm{C} 8$, and $(\mathrm{C} 9)_{\mathrm{n}}$ to form the membrane attack complex (MAC, or C5b-9).

The complement activation products (particularly C5a and MAC) are powerful mediators of inflammation and can induce a variety of cellular activities, including the release of proinflammatory molecules (1-6). Complement can also cause tissue damage directly, because of membrane deposition of the cytolytic MAC. It is now clear that complement plays an important role in the pathology of many autoimmune and inflammatory diseases, and that it is also responsible for many disease states associated with bioincompatibility, e.g., postcardiopulmonary inflammation and transplant rejection (7-13).

Human cells are normally protected from inappropriate complement activation by various membrane-bound complement inhibitors $(14,15)$. These molecules include complement receptor 1 (CR1), decay-accelerating factor (DAF), and membrane cofactor protein
(MCP), which inhibit the early complement activation pathway and the generation of C3 convertase. CD59 is an inhibitor of the terminal complement pathway. CD59 is a widely distributed $18-21-\mathrm{kDa}$ glycoprotein attached to the plasma membrane by a glycosyl-phosphatidylinositol (GPI) anchor, and functions by preventing assembly of the terminal lytic MAC.

Recombinant soluble complement inhibitors based on membrane inhibitors of complement have been prepared by the removal of membrane-linking regions. Soluble inhibitors of complement activation function effectively in vitro, and their administration to animals in models of disease has been shown to suppress inflammation and disease pathology (16-23). Nevertheless, there are concerns regarding the clinical use of systemic inhibitors of complement activation, because activation pathway products play a crucial role in immunity to infection and immune complex catabolism (24-28). A potential advantage of CD59-based inhibitors over inhibitors of complement activation is that CD59 will block MAC formation but will not affect the generation of C3 and C5 activation products. In this respect, MAC has been implicated in the pathogenesis of several autoimmune and inflammatory diseases $(9,29-35)$. CD59 may also be clinically useful for providing protection from complementmediated hyperacute rejection of xenotransplanted tissue. It has been shown that human CD59 and/or DAF expressed on the surface of transgenic pig tissue can considerably prolong the survival of transgenic organs when transplanted into primates $(36,37)$. 


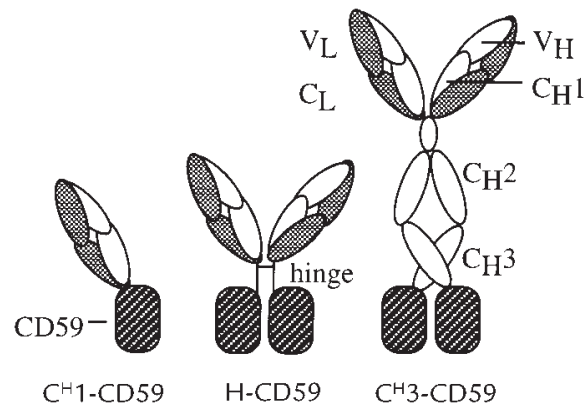

Figure 1

Diagram of antibody-CD59 fusion proteins expected from the expression constructs. Antibody domains are labeled $\left(V_{L}\right.$, variable light; $V_{H}$, variable heavy; $C_{L}$, constant light; $C_{H}$, constant heavy). The specificity of the antibody-combining site (on $V_{L} / V_{H}$ domains) is for the hapten dansyl. Dansyl, 5-dimethylaminonaphthalene-1-sulfonyl.

Soluble untargeted CD59 is not an effective inhibitor of MAC formation in vitro (9), and there are no reports of soluble CD59 being tested in vivo. However, because membrane-bound CD59 provides effective intrinsic protection from MAC formation, the targeting of soluble CD59 to a cell membrane and site of MAC formation may enhance its activity. In this study, we attempt to construct an improved complement inhibitory molecule by joining a soluble CD59 unit to various antibody fragments containing antigen-combining sites. In addition to the potential benefits of targeting a complement inhibitor, the joining of different proteins to immunoglobulin $\gamma$ chains has been shown to increase the half-life of proteins in the circulation and increase binding affinity of the fusion partner due to dimerization by antibody chains. In this feasibility study, antibody fragments specific for the hapten 5-dimethylaminonaphthalene-1-sulfonyl (dansyl) are joined to CD59. Dansyl can be used to label cell surfaces and thus provides a convenient target antigen for in vitro studies using antibody-CD59 fusion proteins. We show that various targeted antibody-CD59 fusion proteins, but not untargeted CD59, effectively protect cells against complement-mediated lysis in an antigen-specific manner.

\section{Methods}

Cell lines. TWS2 is the immunoglobulin nonproducing mouse myeloma cell line Sp2/0, transfected previously with a light chain construct incorporating murine $\kappa$ anti-dansyl variable domain joined to human Cא constant domain (38). TWS2 was cultured in Iscove's Modified Dulbecco's Medium (GIBCO BRL, Grand Island, New York, USA) containing 10\% FCS. Chinese hamster ovary (CHO) cells were grown in DMEM supplemented with $10 \%$ FCS.

DNA, antibodies, and reagents. CD59 cDNA (39) and antiCD59 monoclonal antibody (MAB) 1F5 (40) were kindly provided by H. Okada (Osaka University, Osaka, Japan). AntiCD59 MABs YTH53.1 (41) and P282 were the kind gifts of B.P. Morgan (University of Wales, Cardiff, United Kingdom) and A. Bernard (Hôpital L’Archet, Nice, France), respectively. AntiCD59 MAB MEM43 was purchased from Harlan Bioproducts for Science (Indianapolis, Indiana, USA). Normal human serum (NHS) was obtained from the blood of healthy volunteers in the laboratory and stored in aliquots at $-70^{\circ} \mathrm{C}$. Rabbit
anti-CHO cell membrane antiserum was prepared by inoculation with $\mathrm{CHO}$ cell membranes by standard techniques (42). Anti-dansyl IgG4 was prepared by antigen affinity chromatography as described previously (43).

Construction of antibody-CD59 fusion proteins. cDNA encoding a soluble CD59 functional unit (residues 1-77) (44) was generated by PCR amplification to contain a blunt $5^{\prime}$ end and an Eco R1 site at its 3' end. The GPI-addition signal sequence of CD59 was deleted in product preparation. The PCR product was blunt-end ligated in frame to the $3^{\prime}$ end of a Ser-Gly encoding spacer sequence $\left(\mathrm{SG}_{4} \mathrm{SG}_{4} \mathrm{SG}_{4} \mathrm{~S}\right)$. Using unique restriction sites generated in the human IgG3 heavy-chain constant region (45), the spacer-CD59 sequence was inserted at the $3^{\prime}$ end of various human IgG3 heavy-chain encoding regions. CD59 was inserted (5'-blunt/EcoR1-3') after the heavy-chain constant region 1 $\left(\mathrm{C}_{\mathrm{H}} 1-\mathrm{CD} 59\right)$ exon, immediately after the hinge $(\mathrm{H})$ region at the $5^{\prime}$ end of the $\mathrm{C}_{\mathrm{H}} 2$ exon (H-CD59), and after the $\mathrm{C}_{\mathrm{H}} 3$ exon $\left(\mathrm{C}_{\mathrm{H}} 3-\right.$ CD59). For expression, the IgG-CD59 gene constructs were subcloned into the expression vector 4882PAG, which contains the murine heavy-chain anti-dansyl variable region $(45,46)$. The constant region sequences in the 4882PAG vector were replaced by the IgG-CD59 constructs using unique Bam HI and Sal I sites $(45,46)$. For the $\mathrm{C}_{\mathrm{H}} 3$-CD59 construct, human IgG3 heavychain constant region was replaced by human IgG4 (47).

Transfection and clone selection. 4882PAG/IgG-CD59 expression plasmid constructs were transfected into TWS2 cells using lipofectamine, according to the manufacturer's instructions (GIBCO BRL). Three days after transfection, medium containing $1 \mu \mathrm{g} / \mathrm{ml}$ mycophenolic acid, $2.5 \mu \mathrm{g} / \mathrm{ml}$ hypoxanthine, and $42 \mu \mathrm{g} / \mathrm{ml}$ xanthine was added to the cells for selection of stable transfected populations. After 3 weeks in selection medium, transfectoma clones expressing IgG-CD59 proteins were isolated by assaying culture supernatant for IgGCD59 fusion proteins by ELISA (see below). High-expressing clones were selected by dilution method.

ELISA and protein assays. Detection of IgG-CD59 fusion proteins and their relative concentrations was accomplished using a standard ELISA technique (42). Briefly, microtiter plates were coated with dansylated BSA (see below; $100 \mu \mathrm{g} / \mathrm{ml}$ overnight at $4^{\circ} \mathrm{C}$ ) and then blocked with $2 \%$ BSA in PBS. Culture supernatant containing fusion proteins or purified sam-

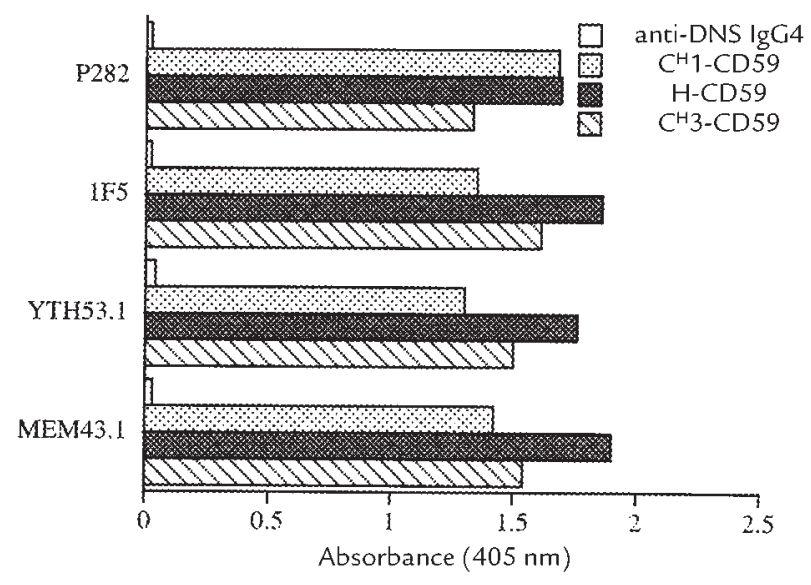

Figure 2

Binding of IgG-CD59 fusion proteins containing conformation-sensitive CD59 epitopes to dansyl. Purified IgG-CD59 fusion proteins (100 $\mathrm{ng} / \mathrm{ml}$ ) or anti-dansyl lgG4 control antibody were incubated in dansylated BSA-coated microtiter plates. Using standard ELISA technique, bound IgG-CD59 was determined using a panel of anti-CD59 MABs that recognize conformational epitopes on CD59. DNS, dansyl; MABs, monoclonal antibodies. 


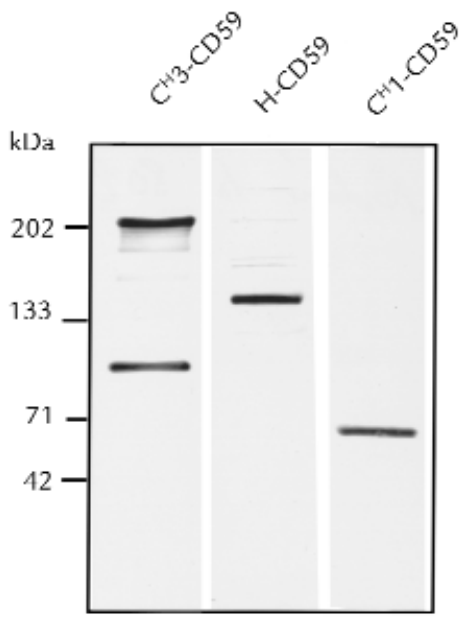

Figure 3

Anti-CD59 Western blot analysis of IgG-CD59 fusion proteins. Purified IgG-CD59 fusion proteins ( $20 \mathrm{ng}$ ) were separated on 4\%-15\% acrylamide nonreducing SDS polyacrylamide gels. Proteins were transferred to nitrocellulose and CD59 immunoreactive bands detected by means of antiCD59 MAB MEM43.

ples in 1\% BSA in PBS was incubated in wells for $1 \mathrm{~h}$ at room temperature, and bound IgG-CD59 was detected by means of anti-CD59 MABs followed by anti-mouse IgG horseradish peroxidase-conjugated antibodies and chromogenic substrate. Protein concentration of IgG-CD59 fusion proteins was determined by either ultraviolet (UV) absorbance (42) or by using a Coomassie protein assay kit (Pierce Chemical Co., Rockford, Illinois, USA).

Fusion protein purification. IgG-CD59 proteins were purified from culture supernatant by anti-CD59 affinity chromatography. Purified anti-CD59 MAB 1F5 or P282 was coupled to HiTrap NHS-activated affinity columns (Pharmacia Biotech, Piscataway, New Jersey, USA), as described by the manufacturer. Culture supernatants containing IgG-CD59 were adjusted to $\mathrm{pH} 7.5$ and applied to affinity columns at a flow rate of $0.5-1$ $\mathrm{ml} / \mathrm{min}$. The column was washed with $6-8$ column vol of PBS, and the fusion protein was eluted with $2-3$ column vol of $0.1 \mathrm{M}$ glycine, $\mathrm{pH}$ 2.6. The fractions containing fusion protein were collected into tubes containing $1 \mathrm{M}$ Tris buffer, $\mathrm{pH}$ 8.0, for neutralization, and dialyzed against PBS.

SDS-PAGE and Western blotting. Purified IgG-CD59 fusion proteins were separated in SDS-PAGE 4\%-15\% acrylamide gradient gels (Bio-Rad Life Science Research, Hercules, California, USA) under nonreducing conditions by standard procedures (48). Gels were stained with Coomassie blue. For Western blotting, separated proteins were transferred to a nitrocellulose membrane, and the membrane was probed with anti-CD59 MAB MEM43 at a 1:500 dilution in TBS buffer (Bio-Rad Life Science Research) containing 3\% nonfat milk. After washing, the membrane was incubated with alkaline phosphatase-conjugated anti-mouse IgG (Sigma Chemical Co., St. Louis, Missouri, USA) at a 1:2,500 dilution in TBS/3\% nonfat milk. The membrane was developed with 5-bromo-4-chloro-3-indolyl phosphate/nitro blue tetrazolium substrate (Sigma Chemical Co.) to reveal CD59-containing bands.

BSA-dansyl labeling of $\mathrm{CHO}$ cells. $\mathrm{CHO}$ cells were labeled with dansyl by coupling dansylated BSA to the $\mathrm{CHO}$ cell surface. To couple dansyl to BSA, $16 \mathrm{mg}$ dansyl (Sigma Chemical Co.) dissolved in $1 \mathrm{ml}$ of acetone was added to $19 \mathrm{ml} \mathrm{BSA} \mathrm{(100} \mathrm{mg}$ in $19 \mathrm{ml}$ of $\mathrm{Na}_{2} \mathrm{CO}_{3}, \mathrm{pH} 9.5$ ) dropwise at $4{ }^{\circ} \mathrm{C}$. The solution was stirred at $4^{\circ} \mathrm{C}$ overnight. Excess insoluble dansyl was removed by centrifugation. Unbound ligand was removed using a G25 Sephadex column. The collected G25 flowthrough was dialyzed against $0.85 \% \mathrm{NaCl}, \mathrm{pH} 7$, at $4^{\circ} \mathrm{C}$ overnight, and BSA-dansyl concentration was determined by a Coomassie protein assay kit. To label CHO cells with dansylated BSA, $20 \mu \mathrm{l}$ of dansylated BSA $(5 \mathrm{mg} / \mathrm{ml})$ was added dropwise to $2 \times 10^{6}$ cells suspended in $0.1 \mathrm{ml}$ of $0.85 \% \mathrm{NaCl}$, and $1.5 \mathrm{ml}$ of $\mathrm{CrCl}_{3}(13.2 \mu \mathrm{g} / \mathrm{ml}$ in $0.85 \% \mathrm{NaCl})$ was then added. The cell suspension was incubated at $30^{\circ} \mathrm{C}$ for $30 \mathrm{~min}$ with gentle rotation. The cells were washed twice with PBS, and dansyl labeling of cells was confirmed by flow cytometry (excitation, $362 \mathrm{~nm}$; emission, $550 \mathrm{~nm}$ ).

Flow cytometry. To detect IgG-CD59 binding to dansyllabeled CHO cells, cells were incubated with fusion proteins at $\sim 2 \mu \mathrm{g} / \mathrm{ml}$ final concentration $\left(30 \mathrm{~min}\right.$ at $4^{\circ} \mathrm{C}$ ). Cells were washed twice in DME $\mathrm{M}$ and incubated with anti-CD59 MAB MEM43 (1:500; $30 \mathrm{~min}$ at $\left.4^{\circ} \mathrm{C}\right)$. After washing, FITC-conjugated anti-mouse IgG (Sigma Chemical Co.) was added (1:200; $30 \mathrm{~min}$ at $4^{\circ} \mathrm{C}$ ). Cells were then washed, fixed with $2 \%$ paraformaldehyde in PBS, and analyzed using a FACScan flow cytometer (Becton Dickinson Immunocytometry Systems, (San Jose, California, USA). Simultaneous determination of dansyl-labeled and viable cells in a mixed cell population was performed by two-wavelength fluorescence analysis, using a Coulter Epics Elite(Coulter corp., Miami, Florida, USA). A mixture of unlabeled and dansyl-labeled CHO cells, both antibody sensitized (see below), was incubated with $7.5 \%$ (final) NHS for $45 \mathrm{~min}$ at $37^{\circ} \mathrm{C}$, either with or without $\mathrm{C}_{\mathrm{H}} 1$-CD59 fusion protein. Propidium iodide (PI) $(10 \mu \mathrm{g} / \mathrm{ml}$ final) was added to cells, and cells were analyzed for fluorescence at an excitation of $362 \mathrm{~nm}$ (to detect dansyl labeling) and $565 \mathrm{~nm}$ (to detect dead cells that have taken up PI).

Complement lysis assays. $\mathrm{CHO}$ cells at $60 \%-80 \%$ confluence were detached with versene (GIBCO BRL), washed once, and resuspended to $10^{6} / \mathrm{ml}$ in DMEM. Cells were sensitized to complement by adding rabbit anti-CHO cell membrane antiserum $(10 \%$ final concentration) to cells. An equal volume of NHS diluted in DMEM was then added. After $45 \mathrm{~min}$ at $37^{\circ} \mathrm{C}$, cell viability was determined by either trypan blue exclusion (both live and dead cells counted) or by adding PI $(10 \mu \mathrm{g} / \mathrm{ml})$ and measuring the proportion of PI-stained dead cells by flow cytometry (44). Cells were lysed with $0.01 \%$ saponin for $100 \%$ lysis controls, and heat-inactivated NHS was used for background lysis. Cell lysis assays were typically performed in $1.5-\mathrm{ml}$ microfuge tubes in a final volume of $100 \mu \mathrm{l}$. To determine the effect of IgG-CD59 fusion proteins on cell lysis, purified fusion protein (or anti-dansyl IgG4 control) in PBS was added to dansyl-labeled cells, together with anti-CHO cell sensitizing antiserum (10\% final concentration), and the cells were preincubated for $15 \mathrm{~min}$ before the addition of different concentrations of NHS, as indicated in our figures.

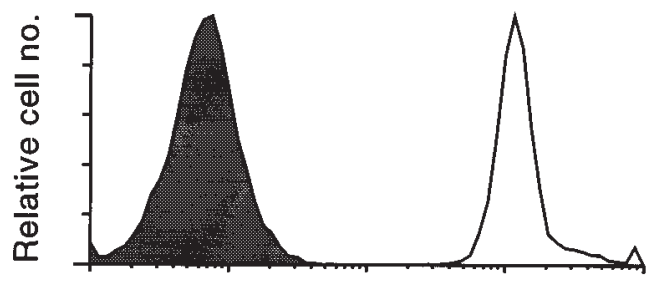

Relative fluorescence

\section{Figure 4}

Dansyl labeling of $\mathrm{CHO}$ cells. Fluorescent BSA-dansyl conjugate was coupled to the $\mathrm{CHO}$ cell surface, and the cells were analyzed by flow cytometry (excitation, $340 \mathrm{~nm}$; emission, $565 \mathrm{~nm}$ ). The relative fluorescence of cells coupled with BSA alone (shaded area) and dansylated BSA (unshaded area) is shown. $\mathrm{CHO}$, Chinese hamster ovary. 


\section{Results}

Construction of antibody-CD59 fusion proteins. cDNA encoding the 77 amino acids of mature CD59 was inserted at the $3^{\prime}$ end of the coding sequence for various IgG heavychain fragments. The resulting constructs encoded a predicted set of fusion proteins consisting of CD59 joined to an antibody-combining site at the end of $\mathrm{C}_{\mathrm{H}} 1$, after the hinge, and after $\mathrm{C}_{\mathrm{H}} 3$ (Fig. 1). Each construct contained human $\operatorname{IgG}$ constant-region genes joined to a mouse anti-dansyl variable region (38). The $\mathrm{C}_{\mathrm{H}} 1-\mathrm{CD} 59$ and $\mathrm{H}-\mathrm{CD} 59$ constructs (Fig. 1) contained human IgG3 constant regions. The $\mathrm{C}_{\mathrm{H}} 3$-CD59 fusion was constructed with a human IgG4 constant region. The IgG4 constant region was used in the $\mathrm{C}_{\mathrm{H}} 3$ construct because IgG3 Fc, but not IgG4 Fc, activates complement.

Expression and characterization of antibody-CD59 fusion proteins. Expression vectors containing heavy chain-CD59 fusion constructs were transfected into the TWS2 cell line that produces an anti-dansyl light chain (see Methods). Transfectoma clones secreting IgG-CD59 proteins with specificity for dansyl were identified by assaying culture supernatant by ELISA. High-expressing clones

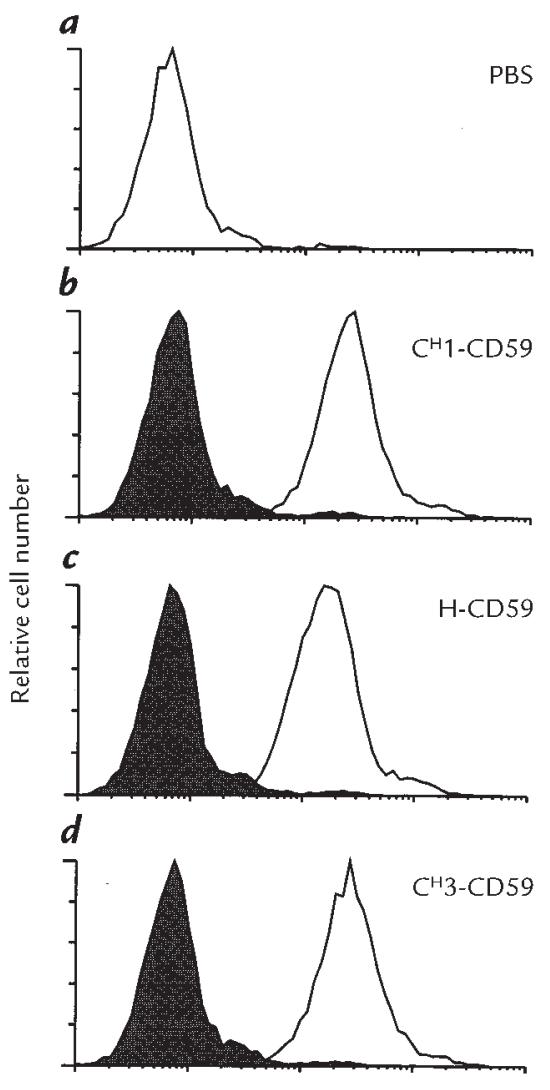

Relative fluorescence

Figure 5

Specific binding of IgG-CD59 fusion proteins to dansyl-labeled cells. Unlabeled or BSA-dansyl-labeled cells were incubated with PBS ( $\boldsymbol{a}$ ) or with IgG-CD59 fusion protein $(\boldsymbol{b}-\boldsymbol{d})$. Binding of IgG-CD59 to cells was detected by flow cytometry using anti-CD59 MAB MEM43 and appropriate FITC-labeled secondary antibody. IgG-CD59 binding to unlabeled cells (shaded areas) and dansyl-labeled cells (unshaded areas) is shown in $b-d$. The figure shows FITC fluorescence, which was separated from dansyl fluorescence by gating. were selected. IgG-CD59 fusion proteins were purified from culture supernatant by anti-CD59 affinity chromatography. Analysis of the purified fusion proteins by ELISA confirmed that each protein construct specifically recognized dansyl, and that the IgG-CD59 constructs that were bound to dansyl were recognized by a series of MABs specific for conformational epitopes on CD59 (Fig. 2). The amount of purified fusion protein isolated from culture medium was estimated at $1 \mu \mathrm{g} / \mathrm{ml}$ for $\mathrm{C}_{\mathrm{H}} 1$ CD59 and $0.3 \mu \mathrm{g} / \mathrm{ml}$ for $\mathrm{H}-\mathrm{CD} 59$ and $\mathrm{C}_{\mathrm{H}} 3-\mathrm{CD} 59$.

SDS-PAGE and anti-CD59 Western blotting revealed that purified $\mathrm{C}_{\mathrm{H}} 1-\mathrm{CD} 59$ and $\mathrm{H}-\mathrm{CD} 59$ have molecular weights of 65,000 and 140,000, respectively (Fig. 3). These molecular weights are consistent with the predicted molecular weights of Fab-CD59 and $\mathrm{F}\left(\mathrm{ab}^{\prime}\right)_{2}$ $(\mathrm{CD} 59)_{2}$. With the $\mathrm{C}_{\mathrm{H}} 3$-CD59 preparation, intermediate antibody chain assemblies are seen. According to molecular-weight analysis, and consistent with previous data on the secretion of recombinant IgG4 (49), $\mathrm{C}_{\mathrm{H}} 3$-CD59 consists predominantly of heavy chain-light chain dimers $\left(\mathrm{H}_{2} \mathrm{~L}_{2}\right)$ and HL forms (molecular weights of 200,000 and 100,000, respectively).

$\mathrm{H}_{2} \mathrm{~L}_{2}$ and $\mathrm{HL}$ forms would both contain dansyl-combining sites, and as predicted, BSA-dansyl-coupled agarose immunoprecipitated both major $\mathrm{C}_{\mathrm{H}} 3$-CD59 forms (data not shown).

Targeting of IgG-CD59 fusion proteins to cell surfaces. To test targeting and complement inhibitory activity of the targeted IgG-CD59 fusion proteins, $\mathrm{CHO}$ cells were labeled with BSA-dansyl. Cell-surface labeling with fluorescent BSA-dansyl was demonstrated by flow cytometric analysis of cells using UV excitation (Fig. 4). Specific targeting of each IgG-CD59 fusion protein to dansyl-labeled CHO cells, but not to unlabeled cells, was shown by means of immunofluorescent flow cytometry using anti-CD59 antibodies (Fig. 5). In a separate experiment performed by anti-CD59 immunofluorescent flow cytometry, it was shown that at a similar molar input concentration of $\mathrm{H}-$ CD59 and $\mathrm{C}_{\mathrm{H}} 3-\mathrm{CD} 59$, a similar relative level of CD59 was bound to the cell surface; an input concentration of $160 \mathrm{nM}$ resulted in a relative mean fluorescence of 326 and 358 (corrected for fluorescence of control $\mathrm{CHO}$ cells) for $\mathrm{H}-\mathrm{CD} 59$ and $\mathrm{C}_{\mathrm{H}} 3$-CD59, respectively.

Protection of cells from complement-mediated lysis by IgGCD59 fusion proteins. Antibody-sensitized $\mathrm{CHO}$ cells are efficiently lysed by human serum complement. However, the incubation with IgG-CD59 fusion proteins provided $\mathrm{CHO}$ cells with some protection from complement-mediated lysis as might be expected from the presence of soluble CD59 (Fig. 6, top). Nevertheless, in comparison to unlabeled $\mathrm{CHO}$ cells, dansyl-labeled $\mathrm{CHO}$ cells were much more effectively protected from lysis by the IgG-CD59 constructs (Fig. 6, bottom). These data show that the targeting of the IgG-CD59 constructs to the cell surface significantly enhances the ability of IgG-CD59 to protect the targeted cells from complement-mediated lysis, and indicate that for CD59 to function effectively, it must be positioned close to the site of MAC formation. This conclusion was further supported by the relative effectiveness of the different IgG-CD59 fusion proteins. At similar input concentrations, $\mathrm{C}_{\mathrm{H}} 1$-CD59 was slightly more effective at protecting dansyl-labeled CHO cells than $\mathrm{H}-\mathrm{CD} 59$, where- 

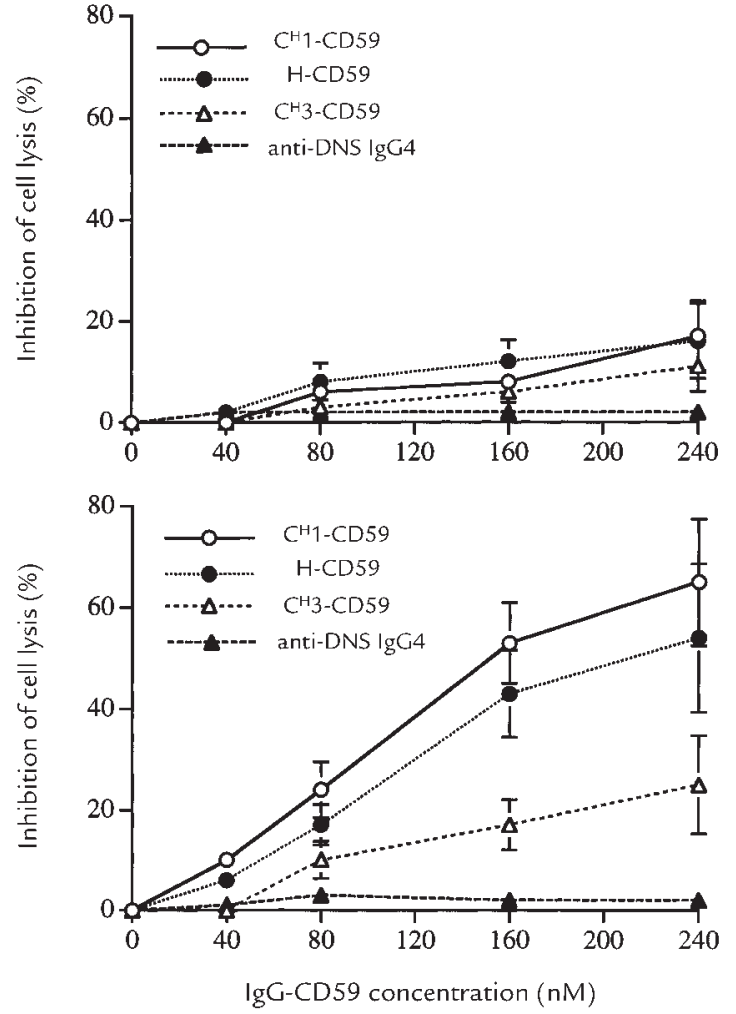

\section{Figure 6}

Inhibition of complement-mediated cell lysis by IgG-CD59 fusion proteins. $\mathrm{CHO}$ cells were incubated with the indicated concentration of $\operatorname{lgG}$ CD59 fusion protein or IgG4 control antibody and then sensitized to complement using anti- $\mathrm{CHO}$ cell membrane antiserum. Human serum, to a final concentration of $10 \%$ (resulting in $75 \%-90 \%$ lysis of unprotected $\mathrm{CHO}$ cells), was then added, and cell lysis was determined after 45 $\min$ at $37^{\circ} \mathrm{C}$. The figure shows the dose response of IgG-CD59 fusion proteins on complement-mediated lysis of unlabeled (top) and dansyllabeled (bottom) CHO cells. Background lysis (cells incubated in heatinactivated human serum) was $<10 \%$ and was subtracted. Results are mean \pm SD of five determinations.

as the relative effectiveness of $\mathrm{C}_{\mathrm{H}} 3-\mathrm{CD} 59$ was less than half that of the other two constructs (Fig. 6). Thus, the farther CD59 was positioned from the antibody-combining site, the less effective an inhibitor it was. In interpreting these data with regard to the relationship between CD59 functional activity and its proximity to the membrane, it is important to note that similar molar input concentrations of $\mathrm{H}-\mathrm{CD} 59$ and $\mathrm{C}_{\mathrm{H}} 3-\mathrm{CD} 59$ resulted in similar levels of cell-bound CD59 (see above).

The protection of $\mathrm{CHO}$ cells from complement-mediated lysis was dose dependent for all IgG-CD59 fusions. In control experiments, $\mathrm{CHO}$ cells were incubated with anti-dansyl IgG4 in place of IgG-CD59 fusion proteins; anti-dansyl IgG4 had no effect on the susceptibility of either unlabeled or dansyl-labeled CHO cells to serum complement (not shown). Dansyl labeling of cells did not affect their susceptibility to complement-mediated lysis in the absence of IgG-CD59 fusion proteins (titrations of cell lysis against serum concentration were performed but are not shown).

The ability of the IgG-CD59 fusion proteins to selectively protect targeted cells in a mixed cell population was determined. Equal numbers of unlabeled and dansyllabeled $\mathrm{CHO}$ cells were mixed, and the relative proportion of unlabeled and labeled cells that were lysed by complement in the presence of either phosphate-buffered saline (PBS) or $\mathrm{C}_{\mathrm{H}} 1-\mathrm{CD} 59$ was determined. Fig. $7 a$ shows that both unlabeled and dansyl-labeled $\mathrm{CHO}$ cells are equally susceptible to complement in the absence of IgGCD59 inhibitor. The concentration of serum used produced $\sim 50 \%$ cell lysis. However, in the presence of $\mathrm{C}_{\mathrm{H}} 1$ CD59, $80 \%$ of dansyl-labeled CHO cells survived serum treatment (Fig. $7 b$, upper quadrants). Consistent with data shown in Fig. 6, top there was also a small relative increase in the survival of unlabeled $\mathrm{CHO}$ cells (compare Fig. 7, a and $b$, lower quadrants). These data show that $\mathrm{C}_{\mathrm{H}} 1-\mathrm{CD} 59$ provides selective protection to targeted (i.e., dansyllabeled) $\mathrm{CHO}$ cells in a mixed cell population.

\section{Discussion}

Inhibition of the complement system may provide an effective strategy for therapy of autoimmune and inflammatory conditions and disease states associated with bioincompatability. A safe and effective pharmaceutical inhibitor of complement is not available, and research has largely focused on developing recombinant soluble inhibitors based on host membrane-bound complement-regulatory proteins, or on developing complement-specific antibodies (50).

In the absence of serum, native and recombinant CD59 containing a GPI anchor will spontaneously insert nonspecifically into cell membranes (51-54) and effectively protect cells from complement-mediated lysis. However, in the presence of serum, CD59 is not effective, probably due to its binding to lipoproteins (55). The effectiveness of soluble CD59 against serum complement-mediated lysis is improved by removal of its GPI anchor, but its activity relative to membrane-bound CD59 is still low (9, 51). In an attempt to develop an improved CD59-based complement inhibitor, we have examined the feasibility of targeting CD59 activity to specific tissues. We report the generation of recombinant IgG-CD59 chimeric fusion proteins that retain both serum complement inhibitory activity and antigen-binding specificity. The IgG-CD59 fusion proteins can be targeted to a specific cell surface and provide the targeted cell with protection from complement-mediated lysis. Untargeted IgG-CD59 fusion proteins were much less effective than their cell-targeted counterparts at inhibiting MAC-mediated cell lysis, indicating that the normal functioning of CD59 requires that CD59 be positioned close to the site of MAC formation. This feature of CD59 function is in contrast to that of inhibitors of complement activation (CR1, DAF, MCP), which function effectively as soluble untargeted proteins.

The univalent $\mathrm{C}_{\mathrm{H}} 1-\mathrm{CD} 59$ fusion protein was the construct most effective at protecting targeted cells from complement-mediated lysis, even though H-CD59 and $\mathrm{C}_{\mathrm{H}} 3$-CD59 both contain dimerized CD59 and bivalent antigen-binding sites. $\mathrm{C}_{\mathrm{H}} 3$-CD59 effectively bound to targeted cells but did not provide efficient protection from complement-mediated lysis. It has been reported previously that some molecules fused at the end of $\mathrm{CH} 3$ lose activity $(56,57)$. However, the relative ineffectiveness of $\mathrm{C}_{\mathrm{H}} 3$-CD59 may be related to its larger size, in 


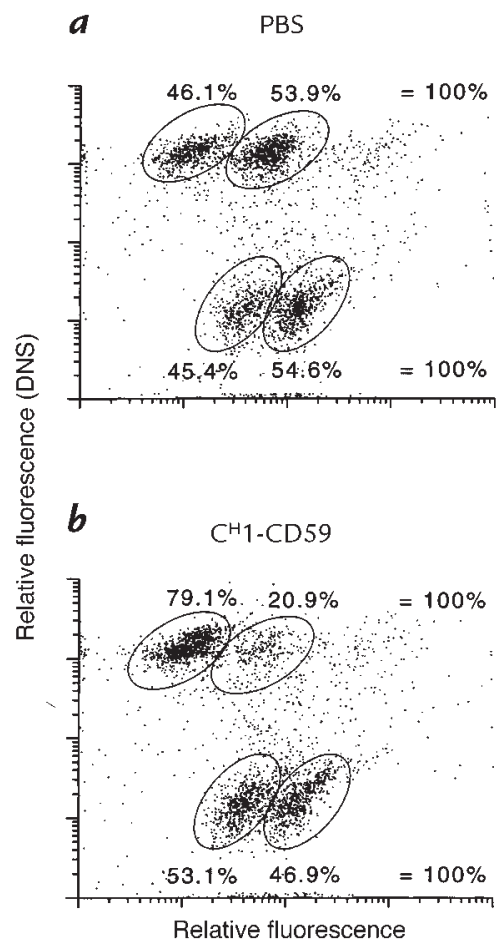

\section{Figure 7}

Selective protection of IgG-CD59 targeted cells in a mixed cell population. PBS (a) or $\mathrm{C}_{\mathrm{H}} 1-\mathrm{CD} 59(160 \mathrm{nM})(\boldsymbol{b})$ was added to a mixed population of unlabeled and dansyl-labeled $\mathrm{CHO}$ cells. Cells were sensitized to complement, and human serum was added, to a final concentration of $7.5 \%$ (resulting in $\sim 50 \%$ cell lysis of unprotected cells). After $45 \mathrm{~min}$ at $37^{\circ} \mathrm{C}$, PI was added and the cells were analyzed by dual-wavelength flow cytometry. Dansyl-labeled cells are identified by ultraviolet excitation (upper quadrants) and dead cells are identified by uptake of PI (right-handside). $\mathrm{Pl}$, propidium iodide.

whichCD59 is likely held at a greater average distance from the targeted cell membrane. Such a conclusion is consistent with our data indicating that CD59 must be in close proximity to the membrane to bind the assembling MAC and prevent cell lysis. In addition, it was shown previously that recombinant membrane-anchored CD59-DAF fusion proteins retained CD59 function only when CD59 was linked directly to the membrane and not when fused distal to DAF (58). In the current study, although CD59 is attached distal to the IgG antigencombining site, the binding of IgG-CD59 via its antigenbinding site(s) does not necessarily fix CD59 at a perpendicular distance from the membrane, as is likely for membrane-anchored DAF-CD59 fusion proteins.

Clearly, the spatial relationship between CD59 and the site of MAC assembly is an important consideration for CD59-based therapeutic complement inhibitors. The linear distance of the spacer peptide used at the IgG $\mathrm{COOH}$ terminus in the IgG-CD59 fusion proteins is about 50 $\mathrm{nm}$. The average diameter of CD59 is about $25 \mathrm{~nm}$, and computer models of IgG-CD59 fusion proteins revealed that a much shorter spacer would be unlikely to interfere with the protein folding and function of either fusion partner. Computer modeling also revealed that it may be possible to prepare a functional construct by linking
$\mathrm{CD} 59$ to the $\mathrm{NH}_{2}$-terminus of the variable region. Such a construct would place the antigen-binding site and the proposed CD59 active site $(44,59)$ in very close proximity to each other. In these studies we have used antibodies specific for the hapten dansyl to protect dansylated $\mathrm{CHO}$ cells. However, with the available vectors, it is straightforward to change the binding specificity of the antibody. Therefore, this approach potentially can be used to provide protection to any cell population recognized by a specific antibody. Potential targets include tissue-specific antigens, markers of inflammation (such as cell adhesion molecules), and foreign antigens on xenotransplanted tissues and organs. However, the location of the epitope on a target antigen will affect the position of bound CD59 relative to the cell membrane and is likely to be an important consideration in the design of an effective tissue-specific IgG-CD59 protein.

Many proteins have been fused with $\mathrm{Fc}$ regions for the purpose of increasing circulatory half-life and increasing their binding affinity due to dimerization by antibody chains. Inhibitors of complement activation (e.g., CR1 [60] and mouse Crry [61]) have previously been fused to IgG fragments but have not been targeted to cells. It is possible that inhibitors of complement activation that act at an early step in the amplification cascade may be more protective of complement-mediated injury than CD59 (an inhibitor of the terminal pathway). However, because early complement pathway activation products are important in host response to infection and immune complex catabolism, there may be circumstances when inhibiting C5b-9 formation, but leaving the complement activation pathway intact, may be of benefit. In this respect, the terminal C5b-9 complex has been implicated in the pathogenesis of several diseases. Our data indicate that only CD59 that is targeted and bound to the site of MAC formation is likely to be a clinically effective inhibitor. The reported approach of targeting complement inhibition may also be appropriate for inhibitors of complement activation, because their targeting would permit a much lower effective serum concentration and would minimize undesirable systemic effects.

\section{Acknowledgments}

We thank Ruben Abagyan for molecular modeling. This investigation was supported by grants AI-34451, CAI-16858, and AI29470 (National Institutes of Health), grant BC962437 (Department of the Army), and a grant-in-aid from the American Heart Association.

1. Gerard, C., and Gerard, N.P. 1994. C5a anaphylatoxin and its seven transmembrane-segment receptor. Annu. Rev. Immunol. 12:775-808.

2. Nicholson-Weller, A., and Halperin, J.A. 1993. Membrane signalling by complement C5b-9, the membrane attack complex. Immunol. Res. 12:244-257

3. Morgan, B.P. 1989. Complement membrane attack on nucleated cells: resistance, recovery and non-lethal effects. Biochem. J. 264:1-14.

4. Ando, B., Wiedmer, T., and Sims, P.J. 1989. The secretory release reaction initiated by complement proteins C5b-9 occurs without platelet aggregation through GPIIb-IIIa. Blood. 73:462-467.

5. Niculescu, F., Rus, H., Biesen, T., and Shin, M.L. 1997. Activation of Ras and mitogen-activated protein kinase pathway by terminal complement complexes is $\mathrm{G}$ protein dependent. J. Immunol. 158:4405-4412.

6. Wang, C., et al. 1995. Hemolytically inactive C5b67 complex: an agonist of polymorphonuclear leukocytes. Blood. 85:2570-2578.

7. Wuerzner, R., and Dierich, M.P. 1997. Complement in human disease. Immunol. Today. 18:460-463. 
8. Morgan, B.P. 1996. Intervention in the complement system: a therapeutic strategy in inflammation. Biochem. Soc. Trans. 24:224-229.

9. Sugita, Y., and Masuho, Y. 1995. CD59: its role in complement regulation and potential for therapeutic use. Immunotechnology. 1:157-168.

10. Morgan, B.P., Gasque, P., Singhrao, S.K., and Piddlesden, S.J. 1997. Role of complement in inflammation and injury in the nervous system. Exp. Clin. Immunogenet. 14:19-23.

11. Squinto, S.P. 1996. Xenogeneic organ transplantation. Curr. Opin. Biotechnol. 7:641-645.

12. Baldwin, W.M., Pruitt, S.K., Brauer, R.B., Daha, M.R., and Sanfilippo, F. 1995. Complement in organ transplantation. Transplantation. 59:797-808.

13. Platt, J.L., et al. 1991. Immunopathology of hyperacute xenograft rejection in a swine-to-primate model. Transplantation. 52:214-220.

14. Parker, C. J. (editor)1992. Membrane defenses against attack by complement and perforins. Curr. Top. Microbiol. Immunol.178:1-188.

15. Liszewski, M.K., Farries, T.C., Lublin, D.M., Rooney, I.A., and Atkinson, J.P. 1996. Control of the complement system. Adv. Immunol. 61:201-283.

16. Weisman, H.F., et al. 1990. Soluble human complement receptor type 1 : in vivo inhibitor of complement suppressing post-ischemic myocardial inflammation and necrosis. Science. 249:146-151.

17. Higgins, P.J., et al. 1997. A soluble chimeric complement activating inhibitory protein that possesses both decay-accelerating and factor I cofactor activities. J. Immunol. 158:2872-2881.

18. Moran, P., et al. 1992. Human recombinant soluble decay accelerating factor inhibits complement activation in vitro and in vivo. J. Immunol. 149:1736-1743.

19. Pemberton, M., Anderson, G., Vetvicka, V., Justus, D.E., and Ross, G.D. 1993. Microvascular effects of complement blockade with soluble CR1 on ischemia/reperfusion injury of skeletal muscle. J. Immunol. 150:5104-5111.

20. Hill, J., et al. 1992. Soluble complement receptor type 1 ameliorates local and remote organ injury after intestinal ischemia-reperfusion in the rat. J. Immunol. 149:1723-1728.

21. Morgan, B.P. 1995. Complement regulatory molecules: application to therapy and transplantation. Immunol. Today. 16:257-259.

22. Piddlesden, S.J., et al. 1994. Soluble recombinant complement receptor 1 inhibits inflammation and demyelination in antibody-mediated demyelinating experimental allergic encephalomyelitis. J. Immunol. 152:5477-5484.

23. Chavez-Cartaya, R.E., DeSola, G.P., Wright, L., Jamieson, N.V., and White, D.J. 1995. Regulation of the complement cascade by soluble complement receptor type 1: protective effect in experimental liver ischemia and reperfusion. Transplantation. 59:1047-1052.

24. Wessels, M.R., et al. 1995. Studies of group B streptococcal infection in mice deficient in complement component $\mathrm{C} 3$ or $\mathrm{C} 4$ demonstrate an essential role for complement in both innate and acquired immunity. Proc. Natl. Acad. Sci. USA. 92:11490-11494.

25. Carroll, M.C. 1998. The role of complement receptors in induction and regulation of immunity. Annu. Rev. Immunol. 16:545-568

26. Prodeus, A.P., Zhou, X., Maurer, M., Galli, S.J., and Carroll, M.C. 1997. Impaired mast cell-dependent natural immunity in complement C3deficient mice. Nature. 390:172-175.

27. Tomlinson, S. 1993. Complement defense mechanisms. Curr. Opin. Immunol. 5:83-89.

28. Law, S.K.A., and Reid, K.B.M. 1988. Complement. IRL Press. Oxford, United Kingdom.72 pp.

29. Kilgore, K.S., Friedrichs, G.S., Homeister, J.W., and Lucchesi, B.R. 1994. The complement system in myocardial ischemia/reperfusion injury. Cardiovasc. Res. 28:437-444.

30. Nangaku, M., et al. 1996. Transfected CD59 protects mesangial cells from injury induced by antibody and complement. Kidney Int. 50:257-266.

31. Nangaku, M., et al. 1997. Renal microvascular injury induced by antibody to glomerular endothelial cells is mediated by C5b-9. Kidney Int. 52:1570-1578.

32. Daniels, R.H., Williams, B.D., and Morgan, B.P. 1990. Human rheumatoid synovial stimulation by the membrane attack complex and other pore-forming toxins in vitro: the role of calcium in cell activation. Immunology. 71:312-316.

33. Holers, V.M. 1995. Complement. In Principles and practices of clinical immunology. R. Rich, editor. Mosby. St. Louis, MO. 363-391.

34. Nangaku, M., Johnson, R.J., and Couser, W.G. 1997. Glomerulonephritis and complement regulatory proteins. Exp. Nephrol. 5:345-354.

35. Wang, Y., et al. 1996. Amelioration of lupus-like autoimmune disease in NZB/W F1 mice after treatment with a blocking monoclonal antibody specific for complement component C5. Proc. Natl. Acad. Sci. USA. 93:8563-8568.
36. McCurry, K.R., et al. 1995. Human complement regulatory proteins protect swine-to-primate cardiac xenographs from humoral injury. Nat. Med. 1:423-427.

37. Byrne, G.W., et al. 1997. Transgenic pigs expressing human CD59 and decay-accelerating factor produce an intrinsic barrier to complementmediated damage. Transplantation. 63:149-155.

38. Poon, P.H., Morrison, S.L., and Schumaker, V.N. 1995. Structure and function of several anti-dansyl chimeric antibodies formed by domain interchanges between human IgM and mouse IgG2b. J. Biol. Chem. 270:8571-8577.

39. Okada, H., et al. 1989. $20 \mathrm{kDa}$ homologous restriction factor of complement resembles T cell activating protein. Biochem. Biophys. Res. Commun. 162:1553-1559.

40. Okada, N., Harada, R., Fujita, T., and Okada, H. 1989. Monoclonal antibodies capable of causing hemolysis of neuraminidase-treated human erythrocytes by homologous complement. J. Immunol. 143:2262-2266.

41. Davies, A., et al. 1989. CD59, an Ly-6 protein expressed in human lymphoid cells, regulates the action of the complement membrane attack complex of homologous cells. J. Exp. Med. 170:637-654.

42. Harlow, E., and Lane, D. 1988. Antibodies: a laboratory manual. Cold Spring Harbor Laboratory Press. Cold Spring Harbor, NY. 726 pp.

43. Tao, M.-H., and Morrison, S.L. 1989. Studies of aglycosylated chimeric mouse-human IgG: role of carbohydrate in the structure and effector functions mediated by the human IgG constant region. J. Immunol. 143:2595-2601.

44. Yu, J., et al. 1997. Mapping the active site of CD59. J. Exp. Med. 185:745-753.

45. Shin, S.-U., Friden, P., Moran, M., and Morrison, S.L. 1994. Functional properties of antibody insulin-like growth factor fusion proteins. J. Biol. Chem. 269:4979-4985.

46. Shin, S.-U., and Morrison, S.L. 1990. Expression and characterization of an antibody binding specificity joined to insulin-like growth factor 1 : potential applications for cellular targeting. Proc. Natl. Acad. Sci. USA. 87:5322-5326.

47. Tan, L.K., Shoppes, R.J., Oi, V.T., and Morrison, S.L. 1990. Influence of the hinge region on complement activation, $\mathrm{C} 1 \mathrm{q}$ binding, and segmental flexibility in chimeric human immunoglobulins. Proc. Natl. Acad. Sci. USA. 87:162-166

48. Laemmli, U.K. 1970. Cleavage of structural proteins during the assembly of the head of bacteriophage T4. Nature. 227:680-685.

49. Shin, S.-U., and Morrison, S.L. 1989. Production and properties of chimeric antibody molecules. Methods Enzymol. 178:459-476.

50. Matis, L.A., and Rollins, S.A. 1995. Complement-specific antibodies: designing novel anti-inflammatories. Nat. Med. 1:839-842.

51. Sugita, Y., et al. 1994. Recombinant soluble CD59 inhibits reactive haemolysis with complement. Immunology. 82:34-41.

52. Rollins, S.A., Zhao, J.I., Ninomiya, H., and Sims, P.J. 1991. Inhibition of homologous complement by CD59 is mediated by a species-selective recognition conferred through binding to $\mathrm{C} 8$ within $\mathrm{C} 5 \mathrm{~b}-8$ or $\mathrm{C} 9$ within C5b-9. J. Immunol. 146:2345-2351.

53. Kooyman, D.L., et al. 1995. In vivo transfer of GPI-linked complement restriction factors from erythrocytes to the endothelium. Science. 269:89-92.

54. van den Berg, C., Cinek, T., Hallett, M.B., Horejsi, V., and Morgan, B.P. 1995. Exogenous glycosyl phosphatidylinositol-anchored CD59 associates with kinases in membrane clusters on U937 cells and becomes Ca2+-signalling. J. Cell. Biol. 131:669-677.

55. Vakeva, A., Jauhianen, M., Ehnholm, C., Lehto, T., and Meri, S. 1994. High-density lipoproteins can act as carriers of glycophosphoinositol lipid-anchored CD59 in human plasma. Immunology. 82:28-33.

56. McGrath, J.P., et al. 1997. Bifunctional fusion between nerve growth factor and a transferrin receptor antibody. J. Neurosci. Res. 47:123-133.

57. Challita, P.M., et al. 1998. A B7.1-antibody fusion protein retains antibody specificity and ability to activate via the $\mathrm{T}$ cell costimulatory pathway. J. Immunol. 160:3419-3426.

58. Fodor, W.L., Rollins, S.A., Guilmette, E.R., Setter, E., and Squinto, S.P. 1995. A novel bifunctional chimeric complement inhibitor that regulates $\mathrm{C} 3$ convertase and formation of the membrane attack complex. $J$. Immunol. 155:4135-4138.

59. Bodian, D.L., Davies, S.J., Morgan, B.P., and Rushmere, N.K. 1997. Mutational analysis of the active site and antibody epitopes of the complement-inhibitory glycoprotein, CD59. J. Exp. Med. 185:507-516.

60. Kalli, K.R., et al. 1991. Mapping of the C3b-binding site of CR1 and construction of a (CR1)2F(ab') 2 chimeric complement inhibitor. J. Exp. Med. $174: 1451-1460$

61. Quigg, R.A., et al. 1998. Blockade of antibody-induced glomerulonephritis with Crry-Ig, a soluble murine complement inhibitor. J. Immunol. 160:4553-4560. 